\title{
INFORME DE RECONOCIMIENTO DEL VALLE DE CHINCHA
}

En los meses de setiembre, octubre y noviembre del presente año se llevó a bajo un reconocimiento del Valle de Chincha por el suscrito, bajo los auspicios de la Comisión Fulbright y del Instituto de Arqueología y Etnología de la Universidad de San Marcos. Mis competentes auxiliares de campo fueron, la Srta. Isabel Flores y los Sres. Luis Lumbreras y Carlos Guzmán; todos estudiantes de arqueología de esta Universidad. El propósito del proyecto arqueológico Fulbright en conjunto, es la investigación de las relaciones existentes en las áreas costeñas principales; y el de mi participación en él, determinar si la parte norte de la costa sur mostraba extensas relaciones con áreas externas en épocas anteriores a la Conquista, y si esto fuera así, en que dirección. El presente informe debe ser considerado como preliminar sobre la parte del trabajo que ha sido completado. El reconocimiento será continuado en los valles del sur, especialmente en el valle de Pisco.

El valle de Chincha está localizado a unos 200 kilómetros al sur de Lima, entre los de Cañete, unos 40 kilómetros más al norte, y el Pisco, a unos 39 kilómetros más al sur. El valle es relativamente pequeño y compacto. Forma un triángulo de 20 kilómetros tierra adentro, en donde el valle se estrecha a menos de medio kilómetro, estando rodeado de montañas bien empinadas.
El piso del valle es relativamente llano y está extensamente cultivado desde las orillas del océano hasta los bordes de los cerros circundantes. Además hay grandes áreas de cultivo en las mesetas que limitan la parte norte del nivel del valle. Esta área incluye la ciudad principal del valle, Chincha Alta.

Existen ahora dos brazos del río que fluye hacia el valle, el Mata Gente al Sur y el río Chico hacia el Norte. Entre estos dos brazos existe un antiguo cauce y al Sur del brazo más meridional del presente río, entre las haciendas San Pedro y Lurinchincha, aparece un cauce del río todavía de más antigüedad.

Los trabajos arqueológicos preliminares llevados a cabo en este valle están casi enteramente limitados a aquellos llevados a cabo por Max Uhle en 1900 y que han sido publicados por Kroeber y Strong en 1924. Uhle pudo encontrar solamente materiales últimos, con la excepción de algunos pocos fragmentos más antiguos.

Con respecto a la cerámica que hemos encontrado en Chincha, el método usado para identificar estilos distintos cronológicamente, fue su aislamiento en sitios particulares, en áreas dentro de grandes sitios, o en depósitos de basura que podían ser examinados por los 
cortes que se habían llevado a cabo en ellos. Estas formas de identificación podían ser verificadas repetidamente en diversos sitios, ya que el plan del reconocimiento indicaba la verificación de todos los sitios que pudieran ser localizados. Como el estudio de los fragmentos colectados está siendo llevado a cabo todavía, muchos puntos ahora dudosos, serán aclarados en su oportunidad.

La cerámica más antigua encontrada en Chincha consiste en un tipo con muchas características de la cerámica Paracas Cavernas. Esta situación sugiere una similaridad con los niveles inferiores de las excavaciones de Lanning en Jahuay, al Norte del valle de Chincha. Los tipos Paracas Cavernas, incluyendo la pintura post-cocción y la decoración en negativo, cerámica simple con marcas conspicuas de pulimento, ollas con bordes simples y engrosados y ceramios con el gollete típico de Cavernas fueron encontrados en varios sitios. El tipo principal con decoración que pudo ser identificado como siguiendo los materiales tipo $\mathrm{Ca}$ vernas, a pesar de que no necesariamente en forma inmediata, está caracterizado por open gambreled bowls con un diseño de líneas diagonales rojas y blancas sobre un fondo negro en la parte exterior de los bordes. La pintura es del tipo pre-cocción. Algunas de estas vasijas presentan complejos diseños en sus interiores, pero ninguno de los fragmentos son suficientemente grande para poder identificar los diseños. Este tipo es único para el área y han sido encontrados solo en Chincha, Nasca y, por lo menos en pequeñas cantidades en Cañete. La forma y la combinación de los colores ocurren en estilo Nasca, en sus fases más antiguas. La evidencia para fijar la antigüedad de este tipo consiste en el hecho de que se presenta asociado en los basurales con cerámica simple muy similar a la del tipo Paracas Cavernas; es, por lo tanto, poco probable que estén muy separados en función del tiempo. También están asociados con una cerámica muy fina, monocroma, de engobe color naranja, presentándose mayormente en forma de vasijas gambreled las cuales se extienden por los menos hasta las fases postreras del Paracas Cavernas, y que son reminiscentes en calidad con la cerámica tipo Necrópolis. Los tipos Necrópolis puros no han sido claramente aislados, a pesar de que han hallado fragmentos tipo post-Cavernas, tales como vasijas con interiores en negro ahumado y pulimentados, así como también en "patrón bruñido" (pattern burnished) o con diseños decorados con estilos (styllus decorated). Ninguno de los tipos decorados post-Cavernas encontrados por Strong en Nasca -diseños incisos combinados con pinturas pre-cocción- pudieron ser encontrados, pero este tipo tampoco ha podido ser hallado en Ica o en Pisco.

El estilo que aparece siguiendo directamente a este tipo rojo y blanco sobre negro, está caracterizado por open gambreled bowls más profundos que los tipos anteriores, decorados en su parte externa por medio de líneas diagonales negras y blancas sobre un fondo natural naranja. Los interiores son de color rojo en los costados con un diseño circular blanco en la base o fondo de la vasija, o también completamente blanco con un diseño pintado alrededor de la parte interna de los bordes. Tales diseños son pintados en rojo y negro, algunas veces se añade el naranja y el gris. A parte de la similaridad en la forma y en las bandas diagonales, la evidencia de que este tipo es cronológicamente el siguiente nos lo proporciona el hecho de que los diseños han sido fijados como las fases 2 y 3 del estilo Nasca en las series estilísticas de Dawson, así como las combinaciones de colores que corresponden al Nasca Temprano (Early Nazca) de Strong. Debe, por lo tanto, estar muy próximo en tiempo con el rojo y el blanco sobre negro, tipo post-Cavernas. Está claramente aislado de tipos más tempranos en los depósitos de basura y ocurre, o se presenta, con diferentes tipos de cerámica simple.

Con respecto a sus relaciones con los estilos Nasca, deberá señalarse que las líneas diagonales en el exterior de las vasijas no ocurre, que yo sepa, ni en el valle de Ica ni en el valle de Nasca. Por el momento me referiré a este tipo en el sentido del Nasca Temprano (Early Nazca) de Strong, a pesar de que los dos tipos no son idénticos.

Siguiendo a este tipo hemos encontrado fragmentos en Chincha de los estilos Nasca B e Y, o se de los estilos Nasca Último y Huaca Loro de Strong. No hay indicios de mucha variación local en estos estilos, esto es, que parecen ser muy similares a la cerámica de los valles al sur. 
Evidencias de cerámica del estilo Tiahuanacoide, o el Horizonte Medio, están confinadas a unos pocos fragmentos encontrados en lo que parece ser un pequeño grupo de tumbas profanadas. La falta de mucha evidencia para estos tipos también ha sido encontrada por Stumer en el valle de Cañete.

Esta situación es difícil de explicar teniendo en cuenta la amplia difusión de estos tipos en la costa peruana. La ausencia de las cerámicas Tiahuanacoides clásicas de la Costa podría deberse a que no se han encontrado todavía cementerios en Chincha en este periodo, o de los anteriores, ya sea por arqueólogos o por huaqueros. Este tipo nunca es frecuente en los depósitos de basura. Lo mismo no puede decirse, sin embargo, de los fragmentos del estilo Epigonal.

Los estilos cerámicos tardíos fueron aislados en los lotes de tumbas por Uhle. Consisten del estilo Chincha Tardío I, el que está íntimamente relacionado con los estilos tardíos del valle de Ica, específicamente en las fases Soniche y Tajaraca determinadas por Riddell. Las similitudes más notables se presentan en los así llamados "diseños textiles" y en las vasijas de bordes biselado (beveled lip bowls). Sin embargo, se pueden identificar varias características locales.

Chincha y las formas de jarra alargadas de este periodo, no están relacionadas con Ica sino con el estilo postrero de Cañete. En el estilo Chincha Tardío II, las características compartidas con el valle de Ica tienden a desaparecer, en cambio, la influencia Inca se hace evidente. También aparecen ejemplares en el más puro estilo Inca, así como réplicas muy próximas a ese estilo.

Tomando ahora otro aspecto de la arqueología del valle de Chincha puede observarse que la variedad de tipos de adobe presentan indicios adicionales para fijar las fechas de los sitios. También se hacen de considerable importancia en aquellos sitios con diversos periodos de ocupación y en donde es de mucho interés determinar la fase particular de ocupación a la cual se podría atribuir una porción particular de arquitectura.
El tipo más temprano de arquitectura consiste en paredes de adobe en la forma de un grano de maíz, o en forma de cuña; estos adobes colocados sobre sus costados. Tales paredes se presentan solas. Posiblemente como paredes de casas, así como también como paredes de terrazas para montículos ceremoniales, en cuyo caso la mayor parte del montículo está compuesto por relleno de toscos adobes irregulares. Adobes en forma de cuña han sido hallados en directa asociación con basura $\mathrm{Pa}$ racas Cavernas. En cierto sitio un depósito de basura con fragmentos del tipo Rojo y Blanco sobre Negro, post-Cavernas, se ha acumulado contra el costado de un montículo de este tipo de adobe. Por lo tanto, el tipo parece ser que comienza en el periodo Cavernas y que ha durado hasta las primeras influencias del estilo Nasca, a pesar que el uso de un relleno de adobes irregulares que tenga precisamente la misma duración, es muy difícil de determinar. El tipo de fragmento Rojo y Blanco sobre Negro es encontrado en asociación con los adobes hemisféricos, los cuales son usados solamente para paredes, y nunca para construcciones masivas y sólidas.

El tipo que fue usado para montículos, y que sigue cronológicamente a los tipos de cuña horizontal y a los de forma irregular, es también en forma de cuña, pero más estrecho en su forma y es usado verticalmente, con la base hacia abajo. Los montículos son construidos sólidamente de este tipo por un proceso de eliminación, este tipo puede ser correlacionado con el tipo cerámico Rojo y Blanco sobre Negro o con los comienzos del Nasca Temprano de Strong. El tipo Nazca Temprano, así como los tipos de estilo Nasca subsiguientes están asociados con los adobes semicilíndricos. Debería ser posible en el futuro distinguir cronológicamente subtipos específicos dentro de este periodo. Los subtipos anotados incluyen un verdadero semicilindro, un arco parabólico y uno con la parte superior cóncava o en forma de medio carrete (half spool type).

En el periodo post-Tiahuanacoide u Horizonte Medio, toda la construcción es de barro sólido o tapia. Sin embargo, al tiempo de la ocupación Inca fueron introducidos los grandes adobes rectangulares. La construcción Inca edificada en la huaca principal de La 
Centinela y que es identificable por los nichos trapezoidales y las puertas de doble jamba, está construida completamente de adobes rectangulares, incluyendo las paredes de las terrazas. Este el único sitio en el que se presenta un uso tan completo de adobes rectangulares. Este tipo ocurre, sin embargo, en pequeñas cantidades, en algunos otros lugares, normalmente asociado con fragmentos de cerámica Inca. La Centinela de San Pedro muestra la interesante característica de presentar varias hiladas de adobes rectangulares usadas como cimientos para las paredes de tapia.

En todos los periodos se utilizó un enlucido de barro para cubrir las superficies de las paredes y terrazas. Las paredes con pintura amarilla ocurren en asociación con los adobes semicilíndricos del periodo Nasca y paredes blancas algunas veces en los edificios tardíos.

La construcción Inca en La Centinela tiene pintados paneles con diseños en las paredes como ha sido reportado por el Dr. Uhle. Una nueva e interesante característica es la ocurrencia de una pared en la huaca de La Centinela propiamente dicha, y que corresponde al periodo tardío de Chincha, la cual está decorada en un friso idéntico en técnica a aquellos de Chanchan, pero con típicos diseños de la Costa Sur. Se deberá mencionar ahora que el uso arquitectónico de la piedra ocurre en casi todos los periodos. En muchos casos parece haber sido usada como sustituto de los adobes en aquellos lugares en donde la piedra podía conseguirse con facilidad; en otros casos esto era, aparentemente, una cuestión de gusto el que se usara piedra o adobe. El único caso de un uso amplio de la piedra para habitaciones ocurre en un grupo de sitios en la parte superior del borde de la meseta que domina la parte superior del valle, cerca de El Carmen. El mayor de estos sitios muestra un amplio uso de las piedras del campo en la construcción de paredes, a pesar de que también se usa los adobes hemisféricos. La basura asociada contiene fragmentos del tipo Rojo y Blanco sobre Negro de la cerámica Temprana Nasca. En otros sitios del periodo Nazca, la abundancia de cantos rodados de río, sugiere que eran usados para algún propósito arquitectónico, pero no pudimos notar que se hicieran paredes con ellos. En los periodos tardíos, se usaban cantos rodados de río y piedras del campo en la construcción de tumbas del periodo tardío Chincha, como revestimiento de las cámaras cúbicas subterráneas que han sido construidas sobre las verdaderas cámaras funerarias. Los mismos materiales fueron usados en el periodo incaico para la construcción de tumbas rectangulares semi-subterráneas parecidas a chullpas y que ocurren al lado de estructuras idénticas hechas de tapia.

En base a las fechas que hemos asignado a los diversos sitios es posible fijar algunas conclusiones con respecto al plan o patrón de asentamientos (settlement patterns) en el valle. Un gran número de asientos tempranos son claramente ceremoniales, de acuerdo con la presencia de grandes montículos sólidos. Estos sitios tienen casi siempre basura de ocupación acumulada a sus costados, en tal forma que es lógico esperar que haya habido algún tipo de habitación en estos sitios. Los sitios de habitación pura de este periodo son raros, y aquellos que existen no muestran indicaciones superficiales del plan de habitación. Sin embargo, cualquier sitio relativamente llano o bajo en el piso del valle debería estar actualmente destruido. La única excepción es la de un sitio previamente mencionado como existente en el borde del desierto que domina el valle, que muestra un área de 500 por 250 m cubiertos de cuartos contiguos de varios tamaños, con una gran plaza cerca de su centro. A este sitio se le ha fijado una contemporaneidad con el Nazca Temprano de acuerdo con los fragmentos y los adobes asociados. El sitio sugiere fuertemente un plan o patrón de asentamiento del tipo de una pequeña ciudad, lo cual es realmente algo extraordinario para un periodo tan temprano, y que pudiera ser comparado con las ciudades amuralladas del periodo Nasca, tales como las de Tambo Viejo en Acarí. Volviendo a la arquitectura ceremonial, existen cinco grandes montículos de construcción de adobes del tipo cuña e irregulares, y que, por lo tanto, pueden ser atribuidos al periodo entre Cavernas y Nasca Temprano. Los montículos promedian de 10 a $12 \mathrm{~m}$ de altura y presentan área sobre la superficie, en forma rectangular, de $150 \mathrm{x}$ 80 m. Todos están orientados de Este a Oeste, con el extremo más alto al Oeste, y que bajan en dos o tres terrazas hacia el Este. En periodos subsiguientes pre-Tiahuanacoides, existen solo pocos montículos de igual tamaño, aun- 
que hay varios de más pequeñas dimensiones. En los periodos tardíos, todos los sitios se presentan en forma de montículos, pero varios de estos, que han sido profusamente cortados por las actividades de los hacendados locales, muestran basura de ocupación y paredes en todos los niveles, así que muchos de estos montículos son sitios de habitación puros, construidos hasta alturas de consideración durante periodos prolongados de ocupación. En base a la regularidad del plan de asentamiento, o a la monumentalidad de la arquitectura, unos pocos sitios tardíos pueden ser clasificados como ceremoniales, entre ellos tenemos La Centinela (de Tambo de Mora), La Centinela de San Pedro y la Huaca de Tambo de Mora. En la mayor parte de otros casos será imposible determinar la función de los montículos, a menos que no se hagan excavaciones. Treinta o cuarenta montículos del periodo tardío, de diversos tamaños, ocurren en diversos lugares del valle; éstos están aislados o se presentan en pequeños grupos de dos a cuatro unidades, sin embargo, existen cinco grupos concentrados de diez o más montículos que pudieran ser clasificados como pequeños centros urbanos, a pesar de que carecen de una planificación central. Por lo tanto, parece ser que ambos sitios de habitación, centralizados y descentralizados, coexistieron durante estos periodos, ya que no existen indicaciones de diferencias cronológicas entre ellos.

Como último tópico, debemos decir algunas pocas palabras referentes a la distribución de los sitios dentro del valle. Primero, la mayoría de los sitios se encuentran localizados en el piso del valle. Aquellos que quedan fuera del área cultivada no están lejos de ella. No se ha localizado sitios dentro de las pampas hacia el sur ni hacia el norte.

La mayoría de la ocupación Cavernas cae hacia el sur del brazo sur del río, y todos ellos a menos de tres kilómetros de distancia del océano; tres sitios adicionales ocurren hacia el norte, todos dentro de la misma distancia con respecto al océano. Los dos sitios ocurren tierra adentro, sobre el borde de la pampa, son posiblemente cementerios.

En los periodos posteriores, pre-Tiahuanacoide, el centro de ocupación se desplaza gradualmente valle arriba, a lo largo del río, a pesar de que la ocupación continuaba en las áreas bajas. Los sitios post-Tiahuanacoides están dispersos a través de todo el valle. La ocupación del periodo Inca, a base de la distribución de los adobes rectangulares, parece estar centrada alrededor de La Centinela de Tambo de Mora y de La Centinela de San Pedro.

Los resultados del recorrido del valle de Chincha han mostrado, según creemos, la validez del plan original de recorridos extensos. A base de estas investigaciones y utilizando el conocimiento que tenemos de otras áreas, se hace posible delinear la historia cultural del valle y estimar así las relaciones externas. Es posible ahora indicar los puntos sobre los que se deberá concentrar la atención en el caso de que se puedan hacer excavaciones de envergadura, así como también en lo referente a aquellos lugares en que las excavaciones no serían de gran provecho. La cuestión de las relaciones externas del valle de Chincha, que era una de las tareas principales del proyecto, podrá ser sumarizada como indicando una conexión básica con el área hacia el Sur, en todos los periodos, a pesar de que las variaciones locales distantes, al menos en los estilos cerámicos, fueron desarrollados en los periodos postCavernas al Nasca Temprano y, de nuevo, en el periodo Chincha Tardío. La única excepción apreciable se encuentra en las relaciones entre Chincha y Cañete en el periodo Chincha Tardío.

Debemos esperar que se arroje más luz sobre estas cuestiones como resultado del recorrido del valle de Pisco, que se iniciará en breve plazo, así como por las excavaciones que se llevarán a cabo en las fases subsiguientes del proyecto. El total de los 108 sitios que hubieron de ser localizados en el valle de Chincha sugiere la gran riqueza de datos arqueológicos a colectarse, realizando otros trabajos en el área.

Lima, enero de 1958. 